\title{
The Pathological Features of Bronchoscopic Lung Volume Reduction Using Sealant Treatment Assessed in Lung Explants of Patients Who Underwent Lung Transplantation
}

\author{
Oren Fruchter $^{\mathrm{a}} \quad$ Ludmila Fridel $^{\mathrm{b}} \quad$ Mordechai R. Kramer $^{\mathrm{a}}$ \\ a Pulmonary Division, and ${ }^{b}$ Pathological Division, Rabin Medical Center, Petach Tikva, and Sackler Faculty of \\ Medicine, Tel Aviv University, Tel Aviv, Israel
}

\section{Key Words}

Emphysema $\cdot$ Lung transplantation · Pathology

The clinical safety and efficacy of bronchoscopic lung volume reduction (BLVR) using bilateral emphysematous lung sealant (ELS) treatment in patients with endstage emphysema has previously been demonstrated [1, 2]. However, scant data are available regarding the longterm histological effects of ELS treatment on lung tissue.

Out of 70 patients who received ELS treatment at our center, 5 (aged 56-67 years) subsequently underwent lung transplantation (LTX). The time from BLVR to LTX ranged from 9 to 24 months (median 10 months). In these patients, BLVR served as a bridge to LTX, as their quality of life did not improve significantly following the procedure.

Explanted lungs were harvested and sectioned tissue blocks examined by light microscopy. In all 5 patients, a similar histological pattern at the treatment sites was noted consisting of focal non-necrotizing granulomatous inflammation containing epitheliod cell granulomas and Langerhan's type giant cells indicative of a foreign body reaction (fig. 1). In the 3 patients who had undergone ELS treatment within 12 months of LTX, deposits of hyalonoid amorphous material, indicative of residual foam sealant, were detected within alveoli (fig. 2). There were no signs of tissue necrosis or dysplasia. Note, there were no histological features of fibrosis in the treatment sites or in adjacent areas.

This is the first report in humans of the long-term histological effects of BLVR using ELS therapy. Despite the fact that our conclusions are based on a small number of patients, this histological confirmation regarding the long-term effects of the administered sealant adds important data regarding its safety profile.

\footnotetext{
References $D_{1}$ Herth FJ, Gompelmann D, Ernst A, Eberhardt R: Endoscopic lung volume reduction. Respiration 2010;79:5-13.

- Gasparini S, Zuccatosta L, Bonifazi M, Bolliger CT: Bronchoscopic treatment of emphysema: state of the art. Respiration 2012;84: 250-263.
}

\section{KARGER}

E-Mail karger@karger.com www.karger.com/res (c) 2013 S. Karger AG, Basel

0025-7931/13/0862-0143\$38.00/0
Oren Fruchter, MD, FCCP

The Pulmonary Division, Rabin Medical Center

Petach Tikva, and Sackler Faculty of Medicine

Tel Aviv University, Tel Aviv (Israel)

E-Mail orenfr@ clalit.org.il 


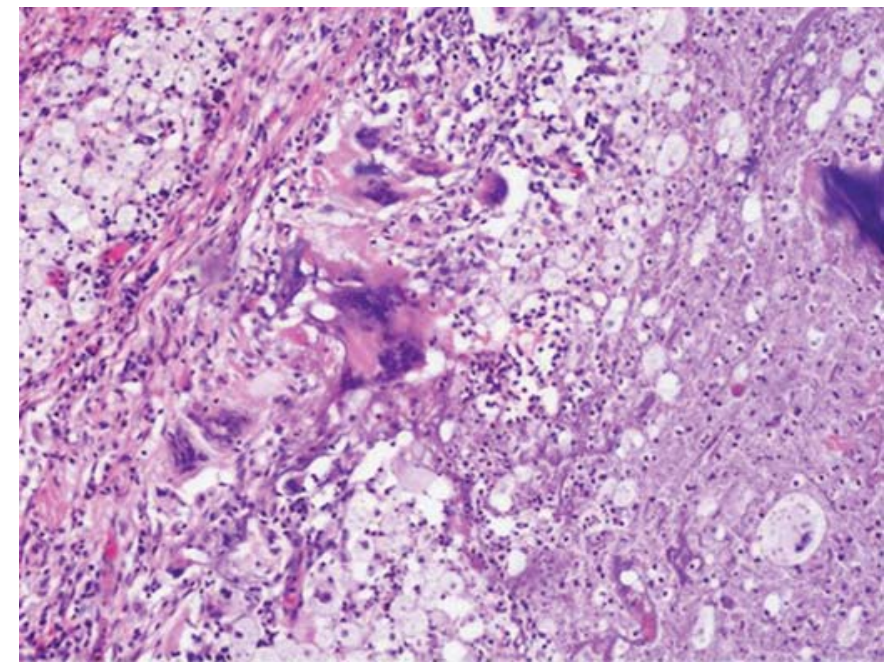

Fig. 1. Explanted lung from a patient that underwent lung sealant treatment showing giant cell reaction and non-necrotizing granuloma.

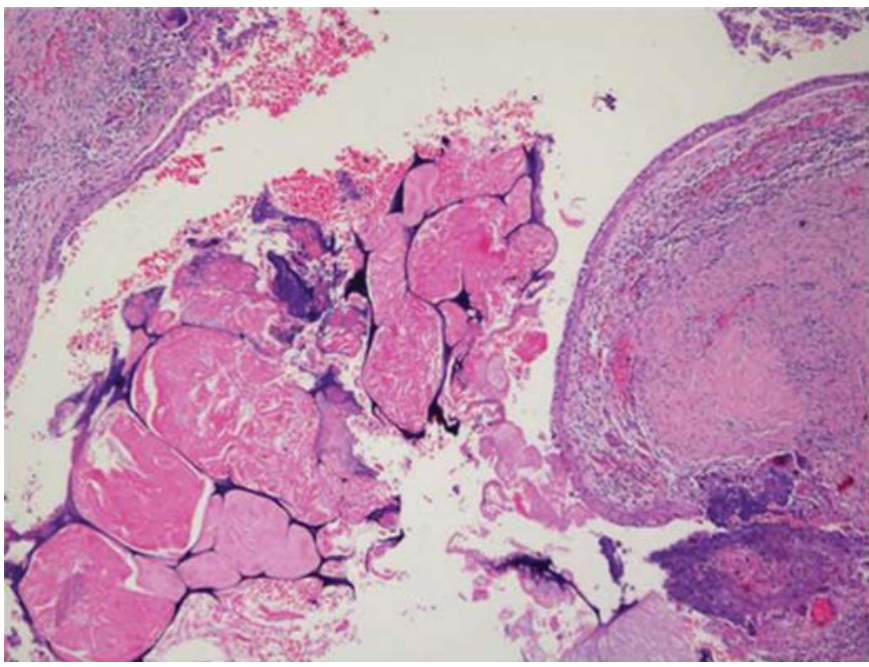

Fig. 2. Explanted lung from a patient that underwent lung sealant treatment nine months prior to lung transplantation showing intra-alveolar deposits of hyalonoid amorphous material (sealant material). 